\title{
Elucidation of the Chemical Role of the Pyroclastic Materials on the State of Conservation of Mural Paintings from Pompeii
}

Silvia Pérez-Diez, Luis Javier Fernández-Menéndez, Dr. Héctor Morillas, Dr. Alberta Martellone, Dr. Bruno De Nigris, Dr. Massimo Osanna, Prof. Dr. Nerea Bordel, Dr. Francesco Caruso, Prof. Dr. Juan Manuel Madariaga, Prof. Dr. Maite Maguregui

\begin{abstract}
Pyroclastic strata have always been thought to protect the archaeological remains of the Vesuvian area (Italy), hence allowing their conservation throughout the centuries. In this work, we demonstrate that they constitute a potential threat for the conservation state of the mural paintings of Pompeii. The ions that could be leached from them and the ion-rich groundwater coming from the volcanic soil/rocks may contribute to salt crystallisation. Thermodynamic modelling not only allowed to predict which salts can precipitate from such leaching events but also assisted the identification of additional sources of sulfates and alkali metals to explain the formation of the sulfates identified in efflorescences from the mural paintings of Pompeii. For the future, fluorine, mainly related to a volcanic origin, can be proposed as a marker to monitor the extent of the impact in the mural paintings of Pompeii in situ.
\end{abstract}

Keywords

halides, ion chromatography, portable LIBS, pyroclastic materials, salt crystallisation 